\title{
Exercise prior to a freely requested meal modifies pre and postprandial glucose profile, substrate oxidation and sympathovagal balance
}

\author{
Keyne Charlot, Aurélien Pichon and Didier Chapelot
}

\begin{abstract}
Background: The effects of exercise on glucose and metabolic events preceding and following a freely initiated meal have never been assessed. Moreover, the relationship between these events and sympathovagal balance is not known. The objective of this study was to determine whether exercise prior to a freely requested meal modifies the pre- and postprandial glucose profile, substrate oxidation and sympathovagal balance.

Methods: Nine young active male subjects consumed a standard breakfast (2298 $\pm 357 \mathrm{~kJ}$ ). After $120 \mathrm{~min}$, they either performed 75 min of exercise on a cycle ergometer (EX - 70\% VO $\mathrm{V}_{2 \max }$ ) or rested (RT). Lunch was freely requested but eaten ad libitum only during the $1^{\text {st }}$ session, and then energy intake was fixed across conditions. Glucose and sympathovagal balance were assessed continuously using a subcutaneous glucose monitoring system and analysis of heart rate variability, respectively. Every $5 \mathrm{~min}$, a mean value was calculated for both glucose and sympathovagal balance. Substrate oxidation was determined by calculating the gas exchange ratio when lunch was requested and 180 min after the onset of eating.

Results: Preprandial glucose profiles were found in $72 \%$ of the sessions and with a similar frequency under both conditions. Meals were requested after a similar delay ( $40 \pm 12$ and $54 \pm 10 \mathrm{~min}$ in EX and RT respectively; ns). At meal request, sympathovagal balance was not different between conditions but $\mathrm{CHO}$ oxidation was lower and fat oxidation higher in EX than in RT $(-46 \%$ and $+63 \%$, respectively; both $p<0.05)$. Glucose responses to the meal were higher in incremental (+ 48\%) but not in absolute value in EX than in RT, with a higher fat oxidation (+ 46\%, $p<0.05)$, and a greater vagal withdrawal $(+15 \%, p<0.05)$.

Conclusions: These results show that exercise does not impair preprandial glucose declines at the following meal freely requested, but leads to an increased postprandial glucose response and an elevated fat oxidation, an effect that vagal withdrawal may contribute to explain.

Keywords: Exercise, preprandial glucose decline, interstitial glucose, postprandial glucose, fat oxidation, heart rate variability, sympathovagal balance, freely requested meal
\end{abstract}

\section{Background}

Exercise is now considered to contribute to both the reduction in the prevalence of type 2 diabetes and the improvement of glucose tolerance [1]. The effect on postprandial glucose was observed even after a single bout of exercise $[2,3]$; however, the delay between the exercise session and the test meal is an important parameter. In the immediate post-exercise period and up to $90 \mathrm{~min}$

\footnotetext{
* Correspondence: dchapelot@gmail.com

Université Paris 13, Laboratoire des Réponses Cellulaires et Fonctionnelles à I'Hypoxie, UFR SMBH, 74 rue Marcel Cachin, 93017, Bobigny, France
}

later, postprandial glucose concentrations have been reported to be increased [4-11] or unchanged [5,12-17]. This is thought to be mainly the consequence of reduced insulin concentrations $[5,7,13,14]$. Another hypothesis is that exercise may transiently blunt glucose tolerance by changing the sympathovagal balance. Prior exercise has been shown to stimulate postprandial sympathetic activity [18], leading to a reduction in pancreatic insulin release [19]. In addition, partially impairing vagal activity before a meal resulted in reduced glucose tolerance $[11,20]$, indicating that an exercise-induced withdrawal of
C Biomed Central

(C) 2011 Charlot et al; licensee BioMed Central Ltd. This is an Open Access article distributed under the terms of the Creative Commons Attribution License (http://creativecommons.org/licenses/by/2.0), which permits unrestricted use, distribution, and reproduction in any medium, provided the original work is properly cited. 
vagal activity may also contribute to this effect either directly or indirectly by alleviating the inhibition of sympathetic stimulation [21]. The continuous evaluation of sympathovagal balance is now possible with the analysis of heart rate variability (HRV), a non-invasive method that investigates the autonomic modulation via changes in RR intervals [22] and may be employed to gain insight into the mechanism underlying exercise-mediated glucose tolerance.

Exercise is usually not followed by an increase in hunger or energy intake [23-31]. In some studies, hunger scores were even found to be briefly reduced [23-25]. The mechanism for this absence of energy compensation is not known. Moreover, a longer delay of meal initiation after exercise has been reported [24]. Thus, it is important to study the sequence preceding meals spontaneously initiated. In animals [32] and humans [33-36], meals are requested after a decline in blood glucose, illustrating central glucopenia [37]. It was found that this phenomenon could even discriminate between meals and snacks [33]. To this day, a possible modification of the glucose profile by prior exercise has not been studied. To detect these preprandial glucose declines, a continuous blood withdrawal system allowing measurements every 5 min is required. However, this method is not fully compatible with exercise. Recently, using a subcutaneous glucose monitoring system $\left(\mathrm{CGMS}^{\mathbb{R}}\right)$, these preprandial glucose declines were measured under everyday life conditions [38]. This system represents a promising alternative and is already being used to monitor glucose profiles during exercise in young diabetic patients [39].

The current study was planned with two main objectives. The first was to determine whether prior exercise would alter the neurometabolic state in which a meal is spontaneously initiated. The second was to verify whether the glucose response to this meal would be altered by prior exercise and whether it was accompanied by a change in fat oxidation and sympathovagal balance.

\section{Methods}

\section{Subjects}

Nine healthy, moderately active men were recruited (see Table 1 for characteristics) using board advertisements

Table 1 Subjects' characteristics $(\mathbf{n}=\mathbf{9})$

\begin{tabular}{lc}
\hline Age $(\mathrm{yr})$ & $21.9 \pm 1.8$ \\
Body weight $(\mathrm{kg})$ & $73 \pm 6$ \\
Height $(\mathrm{m})$ & $1.80 \pm 0.06$ \\
Body mass index $\left(\mathrm{kg} \cdot \mathrm{m}^{-2}\right)$ & $22.7 \pm 1.6$ \\
Body fat (\%) & $13.4 \pm 1.5$ \\
Restrained eating score* & $3.3 \pm 2$ \\
$\mathrm{VO}_{\text {2max }}\left(\mathrm{mL} \cdot \mathrm{kg}^{-1} \cdot \mathrm{min}^{-1}\right)$ & $49 \pm 9$ \\
\hline
\end{tabular}

Values are expressed as mean \pm SD.

*F1 score on the Three Factor Eating Questionnaire [40]. in the University area. Their fat mass was measured using an 8-electrode bioelectrical impedance analyzer (Tanita BC 418MA, Tanita Co. NL), and their restrained eating habits were assessed using the Three-Factor Eating Questionnaire [40]. The number of subjects in the study was based on previous studies showing that significant differences in the delay of meal initiation after exercise were reported with 8 subjects $[29,33]$. The subjects were informed about the nature and risks of the experimental procedure prior to giving their written consent. The protocol was officially approved by the representatives of the local arm of the National Ethics Committee (Comité de Protection des Personnes Ile-deFrance $\left.n^{\circ} \mathrm{X}\right)$

\section{Study design}

The study followed a within-subject design with individuals completing the following 2 test conditions in a counterbalanced order: 75 min of exercise (EX) or 75 min of rest (RT). The 2 conditions were completed on the $1^{\text {st }}$ and $3^{\text {rd }}$ of 3 consecutive days with a washout day between them so that the glucose monitor system $\left(\mathrm{CGMS}^{\circledR}\right)$ was inserted only once and kept in place. The procedure is described in Figure 1. On the evening prior to the first test day, the $\mathrm{CGMS}^{\circledR}$ sensor was inserted in the subject's lateral abdominal wall. On the test days (D1 and D3), the subject arrived at the laboratory unit at 08:00 after an overnight fast. He was equipped with a cardiofrequencemeter and then ate his breakfast at 08:30. At 10:15, depending on the randomization; he either rested on a chair (RT) or performed exercise (EX) for $75 \mathrm{~min}$. At $11: 30$, the subject was placed in an isolated room without temporal cues and asked to spontaneously request his lunch when he felt the need to eat. This procedure is the classic one used in studies of spontaneous eating behavior that has been shown to be sensitive to macronutrient or pharmacological manipulations $[41,42]$. Immediately after the subject requested his lunch, gas exchange was measured for $15 \mathrm{~min}$ prior to lunch being served. The time for eating this meal was limited to $30 \mathrm{~min}$. A second $15 \mathrm{~min}$ gas exchange measurement was planned for the $165^{\text {th }}$ min following the onset of lunch. The cardiofrequencemeter was then removed, and the subject was allowed to leave the laboratory. On the $3^{\text {rd }}$ day (D3) of the study, a similar session took place with the second condition. The CGMS $^{\circledR}$ was removed on D3 after the final gas exchange measurement.

\section{Preliminary testing}

At least 3 days prior to the experimental trial, individuals' maximal oxygen consumption $\left(\mathrm{VO}_{2 \max }\right)$ was determined using a maximal workload test conducted on a bicycle ergometer (Ergoselect 100P, Ergoline, Bitz, Deutschland). Subjects wore a facemask (Hans Rudolph, 8940 Series, 


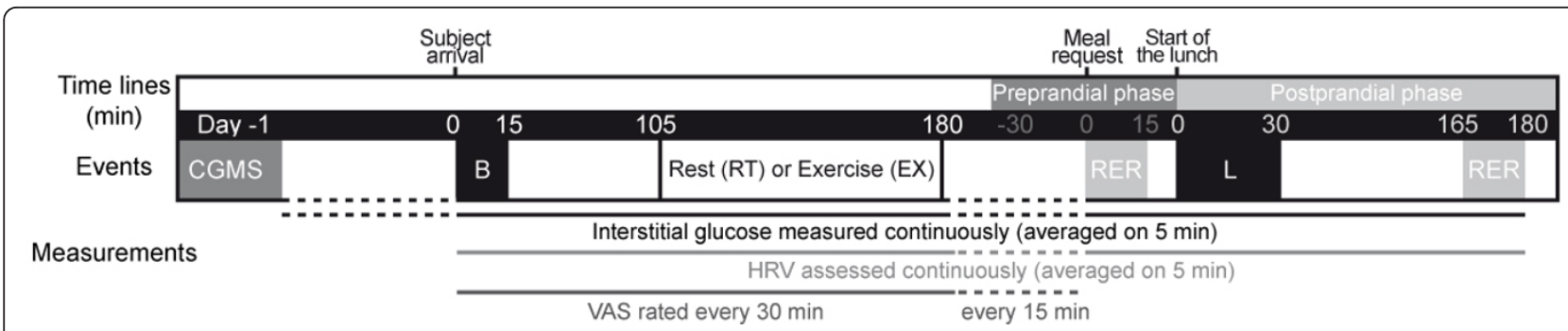

Figure 1 Schedule of experimental events for each subject. The experimental procedure was conducted on 3 successive days with rest (RT) and exercise (EX) as conditions tested in counterbalanced order across subjects (D1 and D3) and separated by a washout day (D2). CGMS, continuous glucose monitoring system; B, breakfast; VAS, visual analogue scales; HRV, heart rate variability; L, freely requested lunch; RER, respiratory exchange ratio.

Kansas City, KA, USA), and gas exchange rates were measured using an open-circuit spirometry $\mathrm{V}_{\max }$ Encore (Viasys Healthcare, Palm Springs, CA, USA). The same equipment was used for all calorimetry measurements throughout the study. The $\mathrm{VO}_{2 \max }$ was considered to be reached when two of the following criteria were met: 1 ) a less than $2 \mathrm{~mL} \cdot \mathrm{kg}^{-1} \cdot \mathrm{min}^{-1} \mathrm{VO}_{2}$ increase despite workload increase; and 2) a respiratory energy ratio (RER) > 1.15.

\section{Foods}

On the eve of each test day, subjects were required to eat their dinner at home at the same hour. The 2 meals consisted of traditional main dishes (couscous and paella) with similar carbohydrate $(\mathrm{CHO})$, fat and protein compositions (33, 43 and 24 energy percent [En\%], respectively). Beverages, dessert and bread were freely added by the subjects before the first session; however, participants were instructed to keep their dinner meals similar before the next session.

On the day of the test, the energy content of the breakfast meal was calculated based on each participant's usual intake at this meal, which ranged from 1700 to $2900 \mathrm{~kJ}$. The same foods were provided for each subject (i.e., bread, butter, marmalade, fruit yogurt and sweetened milk) equal to the energy value calculated for each subject. In addition, the macronutrient composition (in \%) was matched but with an energy value corresponding to their usual breakfast.

The lunch meal consisted of ground beef mixed with mashed potatoes ("hachis parmentier"), bread and fruit yogurt. Subjects were allowed to eat ad libitum on the first day but were required to eat exactly the same amount of each item and at a similar rate on the second test day. The mean energy intake at both breakfast and lunch are shown in Table 2. The 2 conditions were counterbalanced, and the amount served at lunch during the second session was determined after EX for 4 subjects and after RT for 5 subjects. While this may have led to a higher or lower energy load compared to the one that would have been spontaneously consumed, this method was considered to respect the physiological state better than a fixed amount or an amount based on individual body weight and a putative fixed daily energy distribution.

\section{Exercise}

After a 5 min warm-up period at $75 \mathrm{~W}$, the workload was progressively increased for a $10 \mathrm{~min}$ period until the subject reached $70 \%$ of his $\mathrm{VO}_{2 \max }$. This intensity was then maintained for $60 \mathrm{~min}$. Continuous gas exchange allowed for the measurement of energy expenditure (EE) and constant adjustment of the workload so that exercise was maintained at the desired intensity.

\section{Motivation to eat}

From the beginning of breakfast to the end of the 75 min of exercise or rest, motivation to eat was assessed on $100 \mathrm{~mm}$ visual analogue scales (VAS) addressing the questions "Do you feel hungry?" (hunger scale), "Do you want to eat something?" (desire to eat scale) and "How full do you feel?" (gastric fullness scale) every $30 \mathrm{~min}$ for 3 hours, and then every 15 min until a meal was requested. These scales were anchored with "not at all" and "extremely" at the left and right ends, respectively.

Table 2 Energy and macronutrient intake at each experimental meal

\begin{tabular}{lcc}
\hline & Breakfast & Lunch \\
\hline Energy (k) & $2298 \pm 357$ & $5225 \pm 998$ \\
$\mathrm{CHO}(\mathrm{g})$ & $92.8 \pm 15.6$ & $117.4 \pm 22.1$ \\
$\mathrm{CHO}(\%)$ & $67.4 \pm 1.7$ & $37.8 \pm 3.9$ \\
Fat $(\mathrm{g})$ & $12.7 \pm 1.8$ & $63.9 \pm 14.1$ \\
Fat $(\%)$ & $20.9 \pm 1.6$ & $45.8 \pm 3.5$ \\
Protein (g) & $16.0 \pm 2.4$ & $51.3 \pm 10.2$ \\
Protein (\%) & $11.7 \pm 0.4$ & $16.4 \pm 0.4$ \\
\% of TDEE & $22 \pm 4$ & $49 \pm 11$ \\
\hline
\end{tabular}

Values are expressed as mean \pm SD. The experimental meal was ad libitum on the first session, but consumed in the same amount than in the first session on the second session. CHO, carbohydrate. \% of TDEE, percentage of total daily energy expenditure calculated using the Harris \& Benedict equation for resting metabolic rate $(\mathrm{RMR})$ corrected for moderate activities $(\mathrm{RMR} \times 1.4)$. 
The distance between the extreme left and the subject's vertical dash represented the rating score, expressed in $\mathrm{mm}$.

\section{Glucose measurement}

A continuous glucose monitoring system $\left(\mathrm{CGMS}^{\circledR}\right.$, Medtronic Minneapolis, USA) was used to determine the glucose profile. It consists of an electrochemical sensor with glucose oxidase immobilized on an electrode. Interstitial glucose is measured every $5 \mathrm{~min}$. Four calibrations on venous blood taken from the fingertip during a stable state period (i.e., not in the postprandial state) were carried out every $24 \mathrm{~h}$ using the glucometer, Optium Xceed (Witney, Oxon, UK). Interstitial glucose has been reported to be a valid surrogate for the blood glucose level [43] and allows transient glucose fluctuations to be assessed. It is important to note that a lag, varying from 4 to $10 \mathrm{~min}$, between plasma and interstitial glucose levels has been reported, with the former usually preceding the latter [44]. The duration of the lag seems to depend on the glucose level and kinetics. The lag between 2 CGMS $^{\circledR}$ sensors is also important. However, no fixed value has been proposed to this day. Thus, we decided to present and analyze the glucose data without an arbitrary lag.

\section{Energy expenditure and substrate oxidation}

At rest, EE was calculated using the energy equivalent of $\mathrm{O}_{2}$ derived from the Weir equation [45] and substrate oxidation was calculated using the Péronnet \& Massicotte equations [46] with the assumption that protein oxidation is negligible. During exercise, the Jeukendrup \& Wallis equation [47] for moderate to high-intensity exercise $\left(50-75 \% \mathrm{VO}_{2 \max }\right)$ was used to calculate $\mathrm{CHO}$ oxidation and EE. This stoichiometric equation is more appropriate to exercise since it takes into account that only $20 \%$ of the glucose oxidized is derived from plasma, with $80 \%$ being provided by glycogen. Allowing a delay of $10 \mathrm{~min}$ to reach stability, only the last $5 \mathrm{~min}$ of the preprandial and the postprandial measurements were used for analyses.

\section{Assessment of the autonomic nervous system}

Autonomous modulation was evaluated by the frequency domain analysis of HRV. The RR intervals were recorded during the day using a cardiofrequencemeter (T6, Suunto, Finland), stored for analysis and then screened for artifact (less than 2\%). The determination of a suitable series of $256 \mathrm{RR}$ intervals for each 5 min generated indices of HRV that correspond with each value measured by the CGMS ${ }^{\circledR}$. Power spectral analyses were performed with the HRV Analysis Software 1.1 for Windows [48]. Total power in the frequency range $(0-0.40 \mathrm{~Hz})$ was divided into low frequency (LF: $0.04-0.15 \mathrm{~Hz}$ ) and high frequency (HF: $0.15-0.40 \mathrm{~Hz}$ ) bands. The LF band has been attributed to both the vagal and sympathetic modulations, the HF band to vagal modulation and the LF to HF ratio (LF/HF) to the sympathetic modulation of total activity [49]. The use of normalized units (nu) for the HF component $\left(\mathrm{HFnu}=\left(\mathrm{HFms}^{2} /\left(\mathrm{LFms}^{2}+\mathrm{HFms}^{2}\right) \times\right.\right.$ 100) has been recommended [22]. Our subjects breathed spontaneously but reproducibility has been shown to be similar between spontaneous and paced breathing techniques [50].

\section{Data analysis}

Preprandial glucose declines (PPGD) were based on the definitions of Melanson et al. [34,35]: at least 5\% magnitude and 5 min duration. Since the CGMS ${ }^{\circledR}$ only provided an average value every $5 \mathrm{~min}$, and in accordance with our observations from a previous study [33], we decided that the criteria needed to be more conservative. Therefore, we decided that PPGD should be defined by a decline that lasted at least $10 \mathrm{~min}$ (from 2 consecutive time points) and that the meal had to be requested before the return of glucose concentrations to the basal level.

Areas under the curve (AUC) were calculated by the trapezoidal method over the $180 \mathrm{~min}$ following the start of the lunch meal for both the glucose and HRV indices. For glucose, two postprandial AUCs were calculated: an incremental area (values minus basal level, $\mathrm{AUC}_{\mathrm{inc}}$ ), and an absolute level area $\left(\mathrm{AUC}_{\mathrm{abs}}\right)$. The first was used to specifically determine the glucose response to the meal and the second to evaluate whether differences in this response actually resulted in differences in glucose levels.

\section{Statistics}

All variables means and AUCs were compared using paired Student's $t$-tests. Glucose and HRV indices profiles were analyzed using analyses of variance (ANOVA) for repeated measures with condition (RT and EX) and time as within-subject factors. According to the proposed approach of analysis of serial measures [51], time was divided into 4 periods of interest: 1 ) from breakfast to rest or exercise, 2) rest or exercise and the delay until one subject asked for his meal (the interruption of the comparison is due to the reduction in the sample size), 3) prelunch and 4) postlunch. The prelunch period consisted of the 45 min preceding meal intake (i.e., $30 \mathrm{~min}$ before the lunch request and $15 \mathrm{~min}$ during gas exchange measurement). The postprandial period was divided into 30 min periods (6 time points). When an effect was significant, appropriate comparisons using Scheffe's tests were conducted. Statistical significance was set at $\mathrm{p}<$ 0.05. All results are expressed as mean \pm SEM, unless otherwise stated. All data were obtained for 9 subjects except postprandial HRV during which the recording failed for 1 subject. 


\section{Results}

HRV indices, energy expenditure and substrate oxidation during the rest or exercise period

Values and statistical significances are displayed in Table 3. Compared to rest, exercise induced an increase in energy expenditure of $2690 \pm 226 \mathrm{~kJ}$ with $136 \pm 12 \mathrm{~g} \mathrm{CHO}$ and $11 \pm 2 \mathrm{~g}$ fat oxidized. During exercise, LF and HF decreased but the LF/HF ratio increased, demonstrating the shift from sympathovagal balance toward sympathetic activation. As expected, HR dramatically increased during exercise.

\section{Appetite, meal request delay and preprandial glucose declines}

The delay from the end of the exercise or rest period until the lunch request was not significantly different between conditions $(40 \pm 12$ and $54 \pm 10 \mathrm{~min}$ for RT and EX, respectively; ns). Hunger, desire to eat and gastric fullness scores are illustrated in Figure 2. The ANOVA revealed no effect of condition. Based on previous results and on the differences observed in the mean values of our data, comparisons were conducted between conditions at 150, 180 and $195 \mathrm{~min}$. However, they failed to reach significance. Preprandial glucose profiles are shown in Figure 3. According to the defined criteria, 13 of the 18 lunch requests were preceded by a PPGD. The mean magnitude of the trough was $8 \pm 1 \%$ and the mean delay between the onset of the PPGD and the meal request was $25 \pm 3 \mathrm{~min}$. Four of the subjects had a PPGD in both conditions, 3 only in EX and 2 only in RT. In 3 of the 5 profiles without PPGD, a glucose decline was observed but lunch was requested after the value had returned to the baseline level. In 2 of the profiles, the magnitude and duration were less than the required values.

\section{Interstitial glucose}

Glucose profiles are shown in Figure 4A for the absolute values from the beginning of the breakfast to the end of

Table 3 HRV indices, energy expenditure and substrate oxidation during the rest or exercise period

\begin{tabular}{lll}
\hline & Rest & Exercise \\
\hline HR (bpm) & $64 \pm 4$ & $151 \pm 3 \neq$ \\
LF $\left(\mathrm{ms}^{2}\right)$ & $2443 \pm 184$ & $68 \pm 20 \neq$ \\
HF $\left(\mathrm{ms}^{2}\right)$ & $2952 \pm 757$ & $41 \pm 18 \dagger$ \\
HF (n.u.) & $47 \pm 6$ & $21 \pm 3 \dagger$ \\
LF/HF & $1.7 \pm 0.5$ & $8.2 \pm 1.8^{*}$ \\
Energy (kJ) & $418 \pm 39$ & $3109 \pm 222 \neq$ \\
RER & $0.807 \pm 0.008$ & $0.931 \pm 0.003 \neq$ \\
CHO (g) & $10.7 \pm 3.4$ & $146.3 \pm 11.2 \neq$ \\
Fat (g) & $6.3 \pm 0.6$ & $17.6 \pm 1.4^{*}$
\end{tabular}

Values are expressed as mean \pm SEM. HR, Heart rate, LF, Low-frequencies. HF, High-frequencies. RER, respiratory exchange ratio. $\mathrm{CHO}$, carbohydrates. Significantly different from RT, ${ }^{*} p<0.05,+p<0.001, \neq p<0.01$

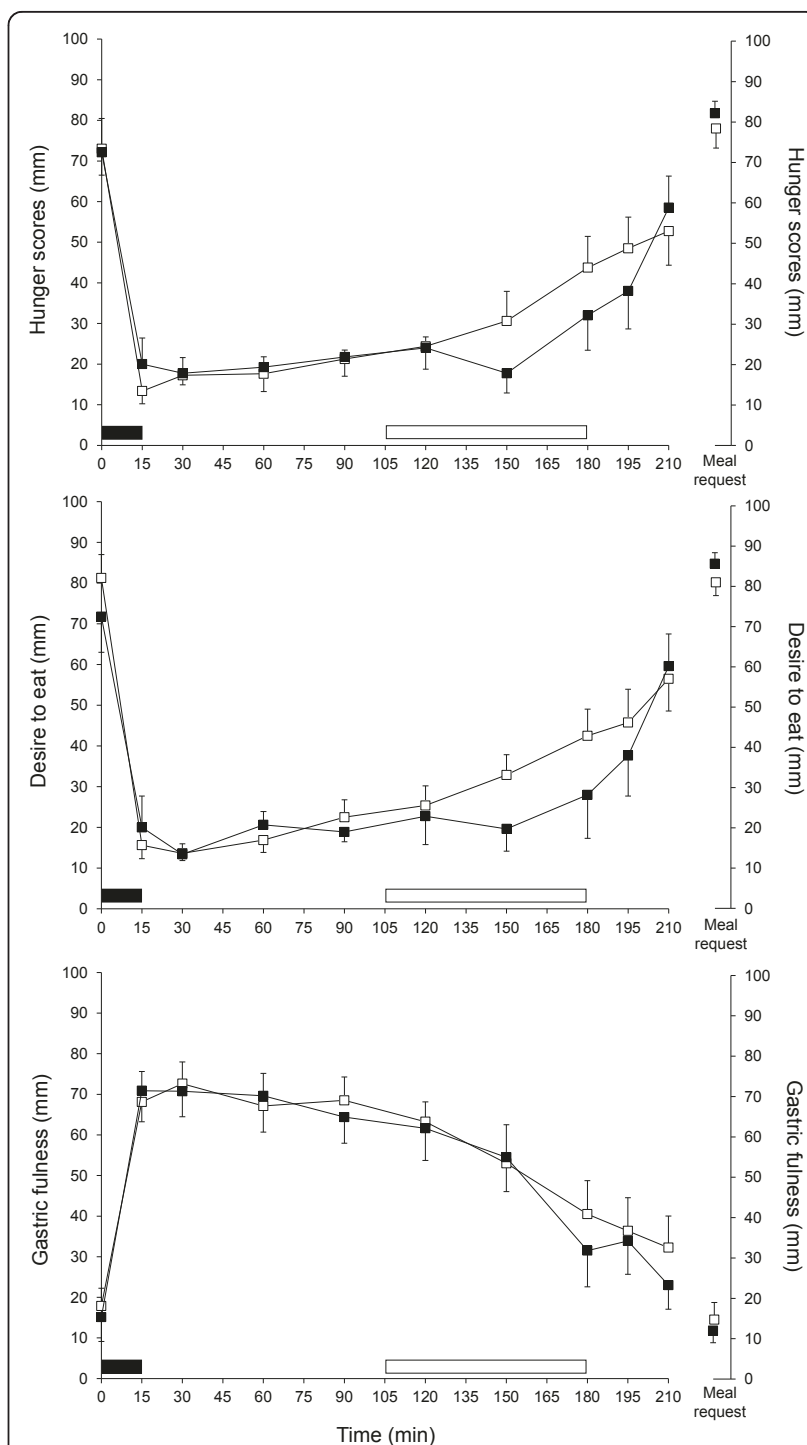

Figure 2 Motivation to eat from the breakfast to the meal request (in $\mathbf{m m}$ ). Hunger (A), desire to eat (B) and gastric fullness (C) scores on each visual analogue scale. The profile was stopped when one subject requested his meal. The black rectangle indicates breakfast intake periods and white rectangle indicates the $75 \mathrm{~min}$ of exercise or rest. All results are mean \pm SEM.

the experimental session ( $3 \mathrm{~h}$ after the lunch) and in Figure 4B for the incremental values during the postlunch period. Analyses of the glucose profiles showed a significant interaction between condition and time $(\mathrm{p}<$ 0.001). Comparisons indicated that the interstitial glucose began to decrease when the exercise intensity reached $70 \% \mathrm{VO}_{2 \max }(120 \mathrm{~min})$ and was lower in EX than in $\mathrm{RT}$ until the end of the exercise (all $\mathrm{p}<0.05$ ). This difference was still significant $25 \mathrm{~min}$ after the end of the exercise period but failed to reach significance in the preprandial period. During the postlunch period, the first glucose peak was reached later in EX than in RT $(67 \pm 9$ and 


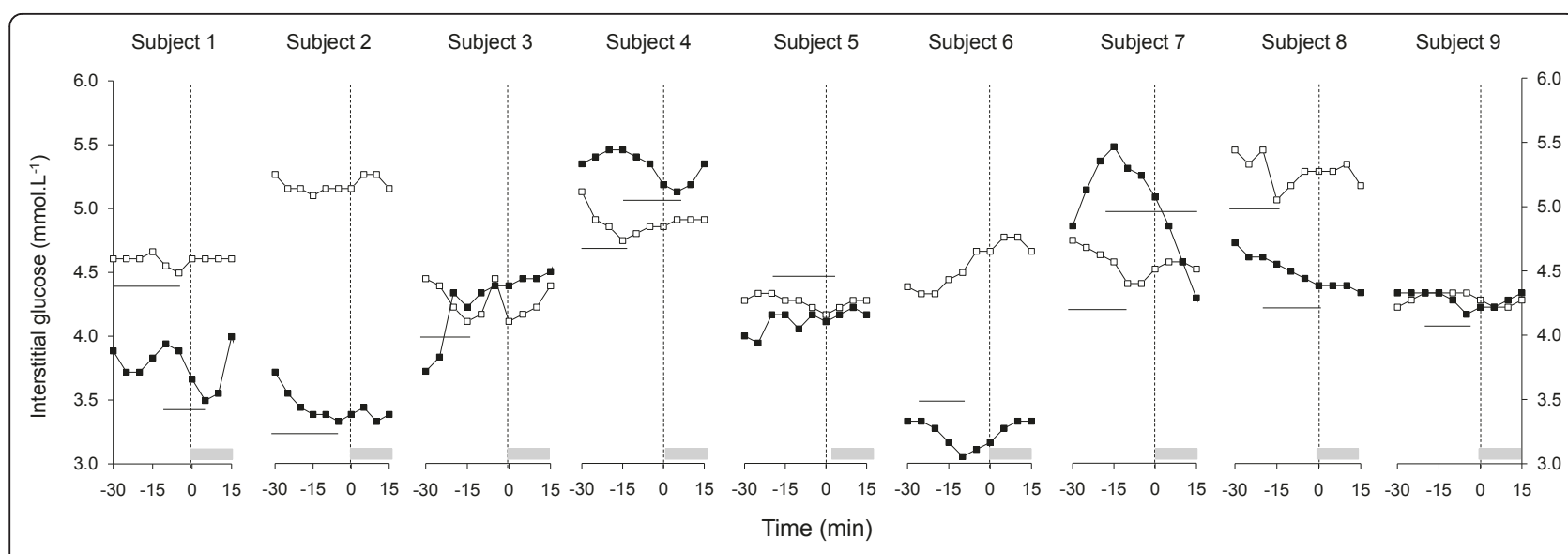

Figure 3 Individual preprandial interstitial glucose concentrations. T = 0 min indicates the meal request. The grey rectangles indicate the 15 min gas exchange periods. The lines indicate the profiles that fulfilled the Melanson et al. criteria for preprandial glucose declines [34] modified for the present study.

$33 \pm 4$ min, respectively; $\mathrm{p}<0.005)$. Moreover, its magnitude was higher in EX than in RT when calculated in incremental units $\left(1.62 \pm 0.30\right.$ and $1.09 \pm 0.16 \mathrm{mmol} \cdot \mathrm{L}^{-1}$, respectively; $\mathrm{p}<0.05)$, but this difference was not significant in absolute values $(5.83 \pm 0.29$ and $5.74 \pm 0.43$ $\mathrm{mmol} \cdot \mathrm{L}^{-1}$, respectively; ns). Analyses of the postprandial glucose profiles showed a significant interaction between condition and time $(\mathrm{p}<0.001)$. Comparisons indicated

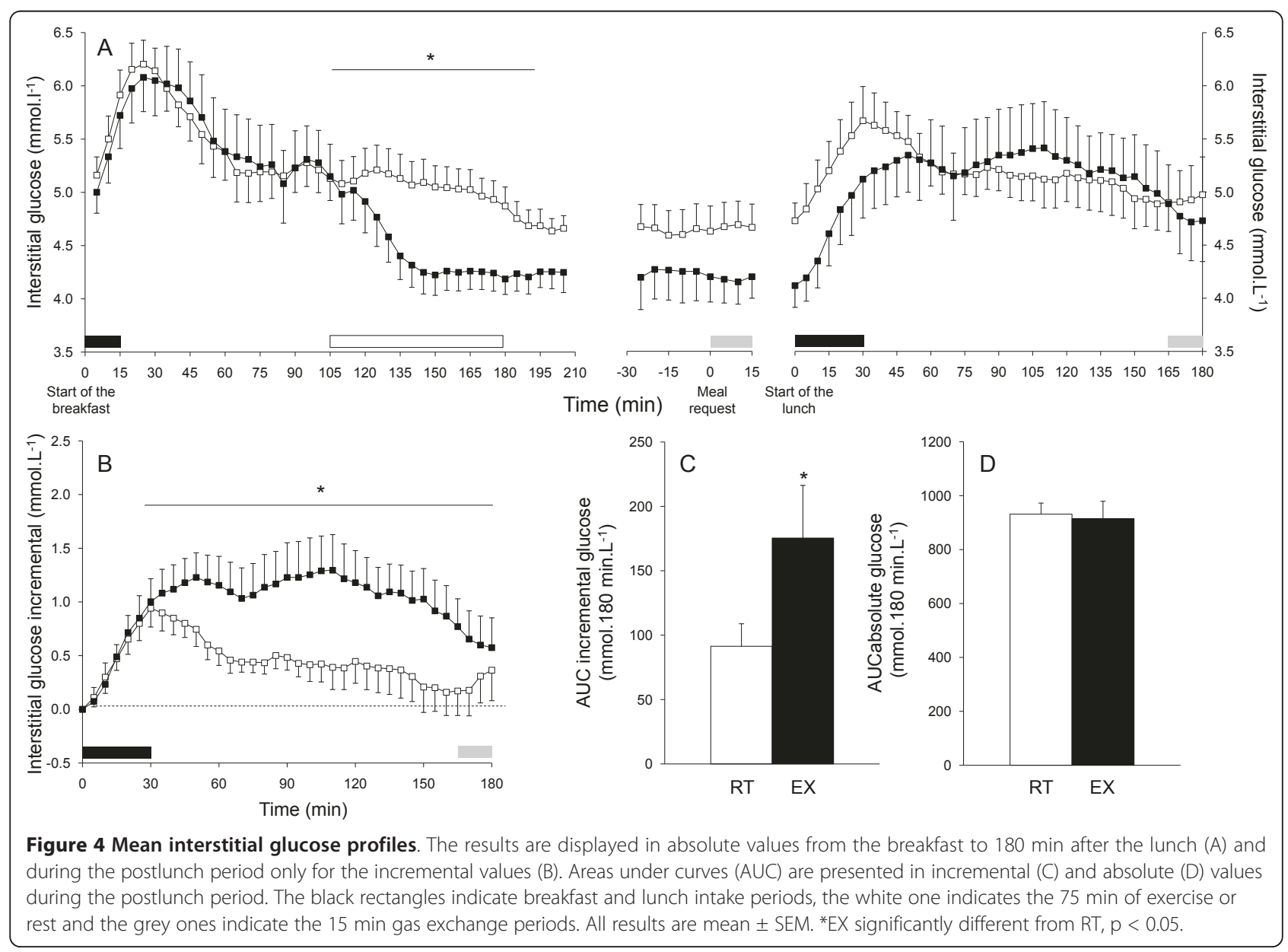


that the glucose response to the meal (i.e., the incremental profile) was higher in EX than in RT between 30 and $180 \mathrm{~min}$ (all $\mathrm{p}<0.05$ ). Consistently, the glucose incremental AUC (Figure 4C) in EX was higher than in RT $(p<0.05)$. No effect of condition was found on the glucose profiles for absolute values and no difference in the absolute AUC (Figure 4D) was observed between conditions.

\section{Pre and postprandial energy expenditure and substrate oxidation}

Results are presented in Table 4. At meal request, RER and $\mathrm{CHO}$ oxidation were lower by $10 \%$ and $46 \%$, respectively; and fat oxidation was higher by $63 \%$ (all $\mathrm{p}<0.05$ ) in EX than in RT. Three hours after lunch, RER and CHO oxidation were still lower by $8 \%$ and $37 \%$, respectively; and fat oxidation was higher by $46 \%$ (all p <0.05) in EX than in RT.

\section{Pre and postprandial heart rate variability indices}

At meal request, an effect of condition was found only for HR ( $\mathrm{p}<0.005)$, and an interaction between time and condition for LFms ${ }^{2}(\mathrm{p}<0.05)$. Comparisons showed that LF was higher in RT than in EX until 15 min prior to the lunch request $(\mathrm{p}<0.05)$ but this difference was not observed afterwards (data not shown). HR was higher in EX than in RT from 30 min prior to the meal request until 15 min after the meal ( $<<0.05$, data not shown).

After lunch, a rapid increase in HR and a decrease in HFms ${ }^{2}$, HFnu and LFms ${ }^{2}$ were observed. The ANOVA showed an effect of condition for HR $(\mathrm{p}<0.001)$, LFms ${ }^{2}$ $(\mathrm{p}<0.01)$, HFms $^{2}(\mathrm{p}<0.05)$ and HFnu $(\mathrm{p}<0.05)$. An interaction between condition and time was found for HR $(\mathrm{p}<0.005)$ and $\mathrm{HFms}^{2}(\mathrm{p}<0.05)$. Comparisons between the postprandial HRV profiles for 30 min periods showed that HR was higher in EX than in RT during the first 150 min and that HFms ${ }^{2}$, LFms ${ }^{2}$ and HFnu were lower in EX than in RT during the first 90 min of the postprandial interval (all $\mathrm{p}<0.05$, Figures 5A, B, C, D and E). When AUCs were analyzed, comparisons showed that postprandial HRV indices in EX were higher than in RT for HR (by $12 \%, \mathrm{p}<0.001$ ) and lower for HFms ${ }^{2}$, HFnu (by $46 \%$ and $15 \%$, respectively; both $\mathrm{p}<0.05$ ) and $\mathrm{LFms}^{2}$ (by $21 \%$; $\mathrm{p}<0.001)$.

\section{Discussion}

In this study, sympathovagal modulation and interstitial glucose concentrations were for the first time recorded continuously and in parallel to assess the effects of exercise on the pre- and postprandial sequences of a spontaneously requested meal. Our results show, firstly, that in young male adults, exercise did not alter the preprandial sequence (delay, motivation to eat, preprandial glucose decline) but that under this condition the meal was requested in a metabolic state that was characterized by a higher proportion of energy being derived from fat. Secondly, the postprandial glucose response was increased in relative but not absolute values after exercise, and this was associated with an increase in fat oxidation and vagal withdrawal.

\section{Prelunch results}

Exercise did not alter the motivation to eat or delay request for the meal. After a similar physical workload, exercise has been reported to reduce hunger ratings in some [23-25] but not all studies [26-31]. This effect was brief $(<10 \mathrm{~min})$ and no longer present at meal onset. Although these results were reported for a study with a similar number of subjects, the non-significant trend that we observed in the immediate post-exercise period for hunger and desire to eat suggests that a larger sample size may be required. While a slightly longer delay (5 min) until eating onset has been previously reported [24], this delay was not significantly changed in our study. Again, a higher number of subjects may be required in order to observe this effect. Therefore, specific research into this matter is needed in the future.

One of our hypotheses was that the glucose decline preceding a meal request would be altered by prior exercise. When an exercise that depleted muscle glycogen was performed on the day before testing, it has been reported that most meals were requested without a prior glucose decline [35]. This was accompanied by a very low RER that was corrected after re-feeding. According to the criteria proposed by Melanson et al. [34,35] that we adapted to be more conservative, a glucose decline was observed before $72 \%$ of lunch requests. In the other cases, glucose actually decreased during the preprandial interval, but the magnitude and duration of our modified

Table 4 Energy expenditure and substrate oxidation at meal request and $3 \mathbf{h}$ after the lunch meal

\begin{tabular}{ccccc}
\hline & \multicolumn{2}{c}{ At meal request } & \multicolumn{2}{c}{ 3 $\mathbf{h}$ after lunch } \\
\hline & Rest & Exercise & Rest & $6.71 \pm 0.23$ \\
EE (kJ/min) & $5.96 \pm 0.12$ & $5.96 \pm 0.31$ & $6.93 \pm 0.17$ & $0.818 \pm 0.030^{*}$ \\
RER & $0.870 \pm 0.021$ & $0.784 \pm 0.027^{*}$ & $0.885 \pm 0.027$ & $0.18 \pm 0.04^{*}$ \\
CHO (g/min) & $0.22 \pm 0.03$ & $0.12 \pm 0.04^{*}$ & $0.28 \pm 0.05$ & $0.10 \pm 0.02^{*}$ \\
Fat (g/min) & $0.06 \pm 0.01$ & $0.10 \pm 0.02^{*}$ & $0.07 \pm 0.01$ & \\
\hline
\end{tabular}

Values are expressed as mean \pm SEM. EE, Energy expenditure. RER, respiratory exchange ratio. CHO, carbohydrates. Significantly different from RT, ${ }^{*} \mathrm{p}<0.05$ 


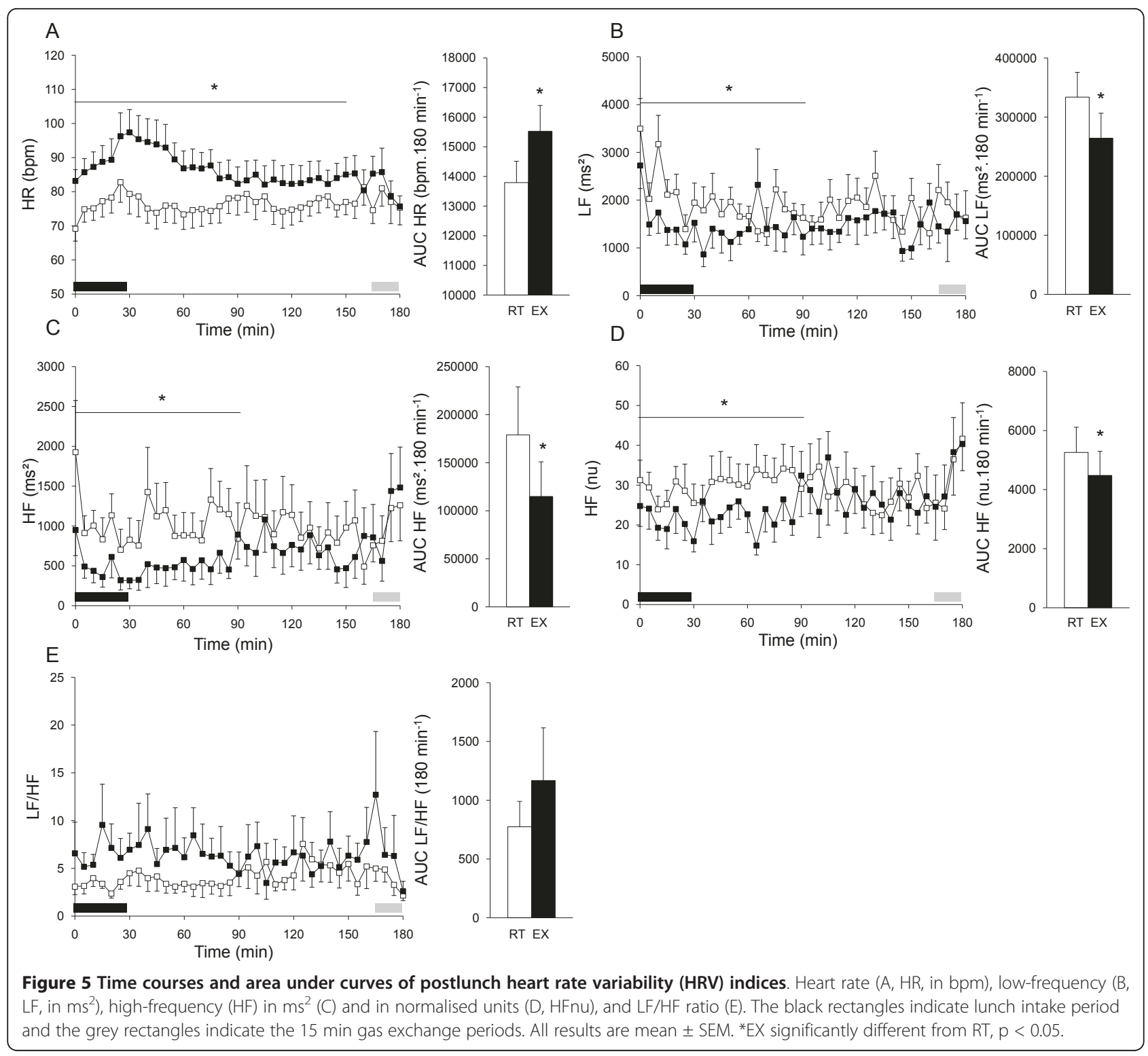

criteria were not fulfilled. The mean delay between the onset of this preprandial glucose decline and the meal request was consistent with previous observations [33-35]. Exercise did not seem to impair this preprandial glucose profile since it was observed with a similar frequency in both conditions. However, our exercise was not designed to deplete muscle glycogen. Based on our glucose oxidation results $(\sim 146 \mathrm{~g})$ and the energy partitioning proposed by Jeukendrup [47] (i.e., $80 \%$ of the glucose oxidized derived from glycogen) and the glucose oxidized at rest $(\sim 11 \mathrm{~g}), \sim 106 \mathrm{~g}$ of glycogen was used $[(146 \times 0.8)-11]$. According to the subjects' leg muscle mass, which was estimated at $\sim 21 \mathrm{~kg}$ by the bioelectrical impedance analyzer, and a mean glycogen muscle concentration of $150 \mathrm{mmol} / \mathrm{kg}$ wet weight, it can be assumed that the exercise depleted glycogen of the whole leg muscle mass by only $18 \%$. In our study, the RER also decreased after exercise when compared with the rest condition, but this did not prevent the occurrence of glucose declines. Therefore, it seems that the glycogen status, more than the exercise per se, is the reason behind the absence of a preprandial glucose decline, or more likely, the absence of its detection.

It must be noted that there was a much larger glucose decline at the onset of the exercise session (from $\sim 5.0$ to $\sim 4.2 \mathrm{mmol} . \mathrm{L}^{-1}$ ), a well-known phenomenon mediated by the increase in muscle glucose uptake [52]. This occurs despite the fact that liver potently increases its glucose output due to lower insulin and higher glucagon and catecholamine secretion [52]. However, when preprandial 
glucose declines were observed, glucose concentrations were in a stable state in each subject.

Between the end of exercise and the meal request, carbohydrate oxidation was $46 \%$ lower than in the rest condition. Considering that $\sim 20 \%$ of the $\mathrm{CHO}$ oxidized during exercise came from blood glucose [47], $20 \mathrm{~g}$ of glucose needed to be compensated for, compared to the rest condition. Although the post-exercise reduction in glucose oxidation could not completely account for the compensation of this glucose difference, it may contribute to preclude an earlier preprandial glucose decline and meal request.

Glucose [36] and ghrelin [53] are the main putative determinants of meal initiation. We have previously reported that ghrelin is increased before meal request [54] but there are arguments against its role as a necessary factor in meal initiation [55]. Moreover, ghrelin was not found to be altered after an exercise session of intensity and duration similar to the one used in our study [56]. Cholecystokinin and glucagon-like peptide-1 have been reported to be increased after a single bout of exercise $[11,56,57]$, but these hormones are involved in satiation or satiety and not in hunger.

Since the HRV indices were not different between conditions at the time subjects requested their meal, it seems that hunger occurs in a similar sympathovagal state after exercise or rest.

\section{Postlunch results}

After exercise, the glucose peak was reached more than 30 min later than after rest. Since the rate of eating was kept similar across conditions, this may indicate that gastric emptying was slowed by prior exercise. The transit time of a $3331 \mathrm{~kJ}$ meal with $67 \%$ fat was not previously reported to be modified by prior exercise [58]. However, mean energy intake at lunch in our study was higher (5225 \pm $998 \mathrm{~kJ})$, and the fat load was lower (45\%) than in this previous study, so that this explanation cannot be excluded.

Based on the incremental profiles, exercise induced a higher postprandial glucose peak level and a $48 \%$ increase in total glucose response to the meal compared with the rest condition. Although our subjects were young and healthy, this could be interpreted as a detrimental effect of exercise since a sustained elevated postprandial glucose level is now considered an independent cardiovascular risk factor [59]. However, the absolute values preclude such a conclusion because the glucose AUC over the 180 min was not different between conditions. These results suggest that this response might be explained by a lower basal glucose level after the exercise session, although it failed to reach statistical significance. It has been demonstrated that exercise consisting of a sufficient workload before a meal can induce a lower postprandial insulin level $[5,7,13,14]$. This has been found to be partially explained by a reduced second-phase insulin secretion [9] and higher insulin clearance [60]. Therefore, the exercise-induced increase in postprandial glucose response might be the result of reduced glucose transport into the muscles due to both lower insulin and a greater glucose output from the splanchnic region, which was facilitated by prior exercise [10]. The increased post-exercise fatty oxidation observed in the muscle might also contribute to the increase in postprandial glucose. It has been documented that increasing fatty acid levels induces an increase in fat oxidation and decreased glucose oxidation via the inhibition of glucose transport/phosphorylation [61]. The involvement of fat oxidation according to the well-known Randle cycle [62] has, to this day, only been demonstrated indirectly [63]. That fat oxidation remained elevated by $46 \%$ in the exercise condition when compared to the rest condition $180 \mathrm{~min}$ after the meal supports this hypothesis. However, it is true that no study has yet demonstrated an increase in plasma glucose concentration due to an increase in fatty acid concentration. This absence has been attributed to a compensatory increase in insulin secretion [64], a phenomenon that might not occur following exercise.

Although increased heart rate indirectly suggests some sympathetic activation, the differences in LF/HF of the HRV analyses failed to reach significance. Interestingly, we actually observed that the previously described postprandial vagal withdrawal [28] was much more pronounced in the exercise than in the rest condition. The fact that this difference involved not only the HFms ${ }^{2}$ but also the HFnu suggests its vagal origin. Pancreatic $\beta$-cells express several $G$ protein-coupled receptors that respond to parasympathetic innervation and in turn increase glucose-stimulated insulin secretion [65]. Recently, the importance of vagal activity was demonstrated using atropine which partially blocked insulin sensitivity in the postprandial period [20]. Thus, the effect of prior exercise on postprandial metabolism could involve postprandial vagal withdrawal and sympathetic activation, both of which would result in a transiently blunted glucose tolerance mediated by reduced insulin secretion $[21,66]$. Importantly, this decrease in global HRV is not consecutive to a lower ability to detect variability [67]. HRV is lower after exercise than after rest because exercise induces a significant decrease in parasympathetic activity and an increase in sympathetic activity (leading to the increased HR) but with a global diminution in global HRV [68]. However, changes in vagal activity that are determined using HRV (i.e., heart branch) are not always associated with consistent changes in hormones, which are known to be highly dependent on the abdominal vagal activity [69]. Therefore, this hypothesis requires further investigation. 


\section{Conclusion}

In young and healthy male adults, a meal is requested during the same preprandial glucose decline after exercise than after rest but in a metabolic state that is characterized by higher oxidation of fat. This difference is still observed $3 \mathrm{~h}$ after meal consumption and is accompanied by a higher glucose response to the meal. Our results suggest that a shift in the sympathovagal balance toward a sympathetic predominance may contribute to this effect of exercise.

\section{List of abbreviations used}

(AUC): Area under the curve; (CHO): carbohydrate; (EE): energy expenditure; (HF): high frequency; (EX): exercise; (HR): heart rate; $\left(H R t_{\max }\right)$ : predicted theoretical maximal heart rate; (HRV): heart rate variability; (LF): low frequency; (PPGD): preprandial glucose decline; (RT): rest; (VAS): visual analogue scale; $\left(\mathrm{VO}_{2 \mathrm{max}}\right)$ : maximal oxygen consumption; (RER): respiratory exchange ratio.

\section{Authors' contributions}

KC managed the subjects, collected and analyzed the data and contributed to their interpretation and the writing of the manuscript. AP helped to collect the data, supervised the analysis and the interpretation of the HRV indices and reviewed the manuscript. DC designed the study, managed the glucose monitoring, helped to collect, analyze and interpret the data and wrote the first draft of the manuscript. All authors read and approved the final manuscript.

\section{Competing interests}

The authors declare that they have no competing interest.

Received: 19 July 2011 Accepted: 24 September 2011

Published: 24 September 2011

\section{References}

1. O'Gorman DJ, Krook A: Exercise and the treatment of diabetes and obesity. Endocrinol Metab Clin North Am 2008, 37:887-903.

2. Bonen A, Ball-Burnett M, Russel C: Glucose tolerance is improved after low- and high-intensity exercise in middle-age men and women. Can J Appl Physiol 1998, 23:583-593.

3. King DS, Baldus PJ, Sharp RL, Kesl LD, Feltmeyer TL, Riddle MS: Time course for exercise-induced alterations in insulin action and glucose tolerance in middle-aged people. J Appl Physiol 1995, 78:17-22.

4. Krzentowski G, Pirnay F, Luyckx AS, Pallikarakis N, Lacroix M, Mosora F, Lefebvre PJ: Metabolic adaptations in post-exercise recovery. Clin Physiol 1982, 2:277-288.

5. Katsanos CS, Grandjean PW, Moffatt RJ: Effects of low and moderate exercise intensity on postprandial lipemia and postheparin plasma lipoprotein lipase activity in physically active men. J Appl Physiol 2004, 96:181-188.

6. Folch N, Peronnet F, Massicotte D, Duclos M, Lavoie C, Hillaire-Marcel C: Metabolic response to small and large 13C-labelled pasta meals following rest or exercise in man. Br J Nutr 2001, 85:671-680.

7. Bielinski R, Schutz $Y$, Jequier E: Energy metabolism during the postexercise recovery in man. Am J Clin Nutr 1985, 42:69-82.

8. Heath GW, Gavin JR, Hinderliter JM, Hagberg JM, Bloomfield SA Holloszy JO: Effects of exercise and lack of exercise on glucose tolerance and insulin sensitivity. J Appl Physiol 1983, 55:512-517.

9. Pestell RG, Ward GM, Galvin P, Best JD, Alford FP: Impaired glucose tolerance after endurance exercise is associated with reduced insulin secretion rather than altered insulin sensitivity. Metabolism 1993, 42:277-282.

10. Rose AJ, Howlett K, King DS, Hargreaves M: Effect of prior exercise on glucose metabolism in trained men. Am J Physiol Endocrinol Metab 2001, 281:E766-771.
11. O'Connor AM, Pola S, Ward BM, Fillmore D, Buchanan KD, Kirwan JP: The gastroenteroinsular response to glucose ingestion during postexercise recovery. Am J Physiol Endocrinol Metab 2006, 290:E1155-1161.

12. Petridou A, Gerkos N, Kolifa M, Nikolaidis MG, Simos D, Mougios V: Effect of exercise performed immediately before a meal of moderate fat content on postprandial lipaemia. Br J Nutr 2004, 91:683-687.

13. Englert V, Wells K, Long W, Hickey MS, Melby CL: Effect of acute prio exercise on glycemic and insulinemic indices. J Am Coll Nutr 2006 25:195-202.

14. Long W, Wells K, Englert V, Schmidt S, Hickey MS, Melby CL: Does prior acute exercise affect postexercise substrate oxidation in response to a high carbohydrate meal? Nutr Metab (Lond) 2008, 5:2.

15. Stiegler P, Sparks SA, Cunliffe A: Moderate exercise, postprandial energy expenditure, and substrate use in varying meals in lean and obese men. Int J Sport Nutr Exerc Metab 2008, 18:66-78.

16. Pfeiffer M, Ludwig T, Wenk C, Colombani PC: The influence of walking performed immediately before meals with moderate fat content on postprandial lipemia. Lipids Health Dis 2005, 4:24.

17. Manders RJ, Van Dijk JW, van Loon LJ: Low-intensity exercise reduces the prevalence of hyperglycemia in type 2 diabetes. Med Sci Sports Exerc 2010, 42:219-225.

18. Matsuo T, Suzuki M: Effects of dietary composition and exercise timing on substrate utilization and sympathoadrenal function in healthy young women. Metabolism 1999, 48:1596-1602.

19. Ahren B, Veith RC, Taborsky GJ Jr: Sympathetic nerve stimulation versus pancreatic norepinephrine infusion in the dog: 1). Effects on basal release of insulin and glucagon. Endocrinology 1987, 121:323-331.

20. Patarrao RS, Lautt WW, Afonso RA, Ribeiro RT, Guarino MP, Fernandes AB, Boavida JM, Macedo MP: Meal-induced insulin sensitization and its parasympathetic regulation in humans. Can J Physiol Pharmacol 2008, 86:880-888.

21. Benthem L, Mundinger TO, Taborsky GJ Jr: Parasympathetic inhibition of sympathetic neural activity to the pancreas. Am J Physiol Endocrinol Metab 2001, 280:E378-381.

22. Montano N, Ruscone TG, Porta A, Lombardi F, Pagani M, Malliani A: Power spectrum analysis of heart rate variability to assess the changes in sympathovagal balance during graded orthostatic tilt. Circulation 1994, 90:1826-1831.

23. Thompson DA, Wolfe LA, Eikelboom R: Acute effects of exercise intensity on appetite in young men. Med Sci Sports Exerc 1988, 20:222-227.

24. King NA, Burley VJ, Blundell JE: Exercise-induced suppression of appetite: effects on food intake and implications for energy balance. Eur $J$ Clin Nutr 1994, 48:715-724.

25. King NA, Blundell JE: High-fat foods overcome the energy expenditure induced by high-intensity cycling or running. Eur J Clin Nutr 1995, 49:114-123.

26. Finlayson G, Bryant $E$, Blundell JE, King NA: Acute compensatory eating following exercise is associated with implicit hedonic wanting for food. Physiol Behav 2009, 97:62-67.

27. Hubert P, King NA, Blundell JE: Uncoupling the effects of energy expenditure and energy intake: appetite response to short-term energy deficit induced by meal omission and physical activity. Appetite 1998, 31:9-19.

28. King NA, Appleton K, Rogers PJ, Blundell JE: Effects of sweetness and energy in drinks on food intake following exercise. Physiol Behav 1999, 66:375-379.

29. King NA, Lluch A, Stubbs RJ, Blundell JE: High dose exercise does not increase hunger or energy intake in free living males. Eur $J$ Clin Nutr 1997, 51:478-483.

30. Lluch A, King NA, Blundell JE: Exercise in dietary restrained women: no effect on energy intake but change in hedonic ratings. Eur J Clin Nutr 1998, 52:300-307.

31. Lluch A, King NA, Blundell JE: No energy compensation at the meal following exercise in dietary restrained and unrestrained women. $\mathrm{Br} J$ Nutr 2000, 84:219-225.

32. Louis-Sylvestre J, Le Magnen J: Fall in blood glucose level precedes meal onset in free-feeding rats. Neurosci Biobehav Rev 1980, 4(Suppl 1):13-15.

33. Chapelot D, Marmonier C, Aubert R, Gausseres N, Louis-Sylvestre J: A role for glucose and insulin preprandial profiles to differentiate meals and snacks. Physiol Behav 2004, 80:721-731. 
34. Melanson K, Westerterp-Plantenga MS, Campfield LA, Saris WH: Blood glucose and meal patterns in time-blinded males, after aspartame, carbohydrate, and fat consumption, in relation to sweetness perception. Br J Nutr 1999, 82:437-446.

35. Melanson KJ, Westerterp-Plantenga MS, Campfield LA, Saris WH: Appetite and blood glucose profiles in humans after glycogen-depleting exercise. J Appl Physiol 1999, 87:947-954.

36. Campfield LA, Smith FJ: Blood glucose dynamics and control of meal initiation: a pattern detection and recognition theory. Physiol Rev 2003, 83:25-58.

37. Routh VH: Glucose-sensing neurons: are they physiologically relevant? Physiol Behav 2002, 76:403-413.

38. Pittas AG, Hariharan R, Stark PC, Hajduk CL, Greenberg AS, Roberts SB: Interstitial glucose level is a significant predictor of energy intake in free-living women with healthy body weight. J Nutr 2005, 135:1070-1074.

39. Adolfsson P, Nilsson S, Lindblad B: Continuous glucose monitoring system (CGMS) during physical exercise in adolescents with type 1 diabetes. Acta Paediatr 2011

40. Stunkard AJ, Messick S: The three-factor eating questionnaire to measure dietary restraint, disinhibition and hunger. J Psychosom Res 1985, 29:71-83.

41. Gatta B, Zuberbuehler C, Arnold M, Aubert R, Langhans W, Chapelot D: Acute effects of pharmacological modifications of fatty acid metabolism on human satiety. Br J Nutr 2009, 101:1867-1877.

42. Marmonier C, Chapelot D, Fantino M, Louis-Sylvestre J: Snacks consumed in a nonhungry state have poor satiating efficiency: influence of snack composition on substrate utilization and hunger. Am J Clin Nutr 2002, 76:518-528.

43. Tavris DR, Shoaibi A: The public health impact of the MiniMed Continuous Glucose Monitoring System (CGMS)-an assessment of the literature. Diabetes Technol Ther 2004, 6:518-522.

44. Boyne MS, Silver DM, Kaplan J, Saudek CD: Timing of changes in interstitial and venous blood glucose measured with a continuous subcutaneous glucose sensor. Diabetes 2003, 52:2790-2794.

45. Weir JB: New methods for calculating metabolic rate with special reference to protein metabolism. 1949. Nutrition 1990, 6:213-221.

46. Peronnet $F$, Massicotte $D$ : Table of nonprotein respiratory quotient: an update. Can J Sport Sci 1991, 16:23-29.

47. Jeukendrup $A E$, Wallis GA: Measurement of substrate oxidation during exercise by means of gas exchange measurements. Int J Sports Med 2005, 26(Suppl 1):S28-37.

48. Niskanen JP, Tarvainen MP, Ranta-Aho PO, Karjalainen PA: Software for advanced HRV analysis. Comput Methods Programs Biomed 2004, 76:73-81.

49. Force Task: Heart rate variability: standards of measurement, physiological interpretation and clinical use. Task Force of the European Society of Cardiology and the North American Society of Pacing and Electrophysiology. Circulation 1996, 93:1043-1065.

50. Pinna GD, Maestri R, Torunski A, Danilowicz-Szymanowicz L, Szwoch M, La Rovere MT, Raczak G: Heart rate variability measures: a fresh look at reliability. Clin Sci (Lond) 2007, 113:131-140

51. Matthews JN, Altman DG, Campbell MJ, Royston P: Analysis of serial measurements in medical research. BMJ 1990, 300:230-235.

52. Goodwin ML: Blood glucose regulation during prolonged, submaximal, continuous exercise: a guide for clinicians. J Diabetes Sci Technol 2010, 4:694-705

53. Blom WA, de Graaf C, Lluch A, Stafleu A, Schaafsma G, Hendriks HF: Postprandial ghrelin responses are associated with the intermeal interval in time-blinded normal weight men, but not in obese men. Physiol Behav 2009.

54. Cummings DE, Frayo RS, Marmonier C, Aubert R, Chapelot D: Plasma ghrelin levels and hunger scores in humans initiating meals voluntarily without time- and food-related cues. Am J Physiol Endocrinol Metab 2004, 287:E297-304.

55. Frecka JM, Mattes RD: Possible entrainment of ghrelin to habitual meal patterns in humans. Am J Physiol Gastrointest Liver Physiol 2008, 294: G699-707.

56. Martins C, Morgan LM, Bloom SR, Robertson MD: Effects of exercise on gut peptides, energy intake and appetite. J Endocrinol 2007, 193:251-258.

57. Bailey DM, Davies B, Castell LM, Newsholme EA, Calam J: Physical exercise and normobaric hypoxia: independent modulators of peripheral cholecystokinin metabolism in man. J Appl Physiol 2001, 90:105-113.
58. Clegg M, McClean C, Davison WG, Murphy HM, Trinick T, Duly E, McLaughlin J, Fogarty M, Shafat A: Exercise and postprandial lipaemia: effects on peripheral vascular function, oxidative stress and gastrointestinal transit. Lipids Health Dis 2007, 6:30.

59. Cavalot F, Petrelli A, Traversa M, Bonomo K, Fiora E, Conti M, Anfossi G, Costa G, Trovati M: Postprandial blood glucose is a stronger predictor of cardiovascular events than fasting blood glucose in type 2 diabetes mellitus, particularly in women: lessons from the San Luigi Gonzaga Diabetes Study. J Clin Endocrinol Metab 2006, 91:813-819.

60. Tuominen JA, Ebeling P, Koivisto VA: Exercise increases insulin clearance in healthy man and insulin-dependent diabetes mellitus patients. Clin Physiol 1997, 17:19-30.

61. Roden M, Price TB, Perseghin G, Petersen KF, Rothman DL, Cline GW, Shulman GI: Mechanism of free fatty acid-induced insulin resistance in humans. J Clin Invest 1996, 97:2859-2865.

62. Randle PJ, Garland PB, Hales CN, Newsholme EA: The glucose fatty-acid cycle. Its role in insulin sensitivity and the metabolic disturbances of diabetes mellitus. Lancet 1963, 1:785-789.

63. Zhang L, Keung W, Samokhvalov V, Wang W, Lopaschuk GD: Role of fatty acid uptake and fatty acid beta-oxidation in mediating insulin resistance in heart and skeletal muscle. Biochim Biophys Acta 2010, 1801:1-22.

64. Boden G, Jadali F, White J, Liang Y, Mozzoli M, Chen X, Coleman E, Smith C: Effects of fat on insulin-stimulated carbohydrate metabolism in normal men. J Clin Invest 1991, 88:960-966.

65. Thorens B: Central control of glucose homeostasis: the brain-endocrine pancreas axis. Diabetes Metab 2010, 36(Suppl 3):S45-49.

66. Ahren B, Holst JJ: The cephalic insulin response to meal ingestion in humans is dependent on both cholinergic and noncholinergic mechanisms and is important for postprandial glycemia. Diabetes 2001 50:1030-1038.

67. Altimiras J: Understanding autonomic sympathovagal balance from short-term heart rate variations. Are we analyzing noise? Comp Biochem Physiol A Mol Integr Physiol 1999, 124:447-460.

68. Hautala A, Tulppo MP, Makikallio TH, Laukkanen R, Nissila S, Huikuri HV: Changes in cardiac autonomic regulation after prolonged maximal exercise. Clin Physiol 2001, 21:238-245.

69. Chang CS, Ko CW, Lien HC, Chou MC: Varying postprandial abdominovagal and cardiovagal activity in normal subjects. Neurogastroenterol Motil 2010, 22:546-551, e119.

doi:10.1186/1743-7075-8-66

Cite this article as: Charlot et al:: Exercise prior to a freely requested meal modifies pre and postprandial glucose profile, substrate oxidation and sympathovagal balance. Nutrition \& Metabolism 2011 8:66.

\section{Submit your next manuscript to BioMed Central and take full advantage of:}

- Convenient online submission

- Thorough peer review

- No space constraints or color figure charges

- Immediate publication on acceptance

- Inclusion in PubMed, CAS, Scopus and Google Scholar

- Research which is freely available for redistribution 